\title{
A Utility Interactive Electricity Generation Schemes with Renewable Resources
}

\author{
${ }^{1}$ T. k. 1.Prasanna, ${ }^{2} \mathrm{~V}$. Vittal Reddy, ${ }^{3} \mathrm{M}$. V.Somashekar \\ ${ }^{1}$ Student, ${ }^{2}$ Associate Professor, ${ }^{3}$ chief mang.tech \\ ${ }^{I}$ Gudlavalleru Engineering College, 2.Gudlavalleru Engineering College, 3.NSIC Hydrabad Gudlavalleru, \\ Krishna District, Andhra Pradesh, India, Pin no.
}

\begin{abstract}
In the recent year's power utility of coastal areas are experiencing relatively large quantum of solar and wind energy. If the wind is heavy it might produce larger sea waves of high energy contents. The electricity needs of a township or a village situated in a coastal area can be partially fulfilled by installing a modular mini electricity generating unit and an intensified solar heat extractor in buildings. Also, installation of medium sized windmill plant, solar heated steam turbine electricity generator and sea wave energy extracting plants could fulfill the rest of the electricity needs of the township. Here we discuss the regulation of the voltage and frequency of a stand-alone fixed-pitch wind energy conversion system (WECS) based on a self-excited squirrelcage induction machine. The characteristics of the wind turbine, self-excited generator, and the ratings of the VSI are considered in order to determine the load range for which voltageand frequency can be regulated for a given wind speed range.
\end{abstract}

Keywords: Solar panel, solar tracker, solar water heater,renewable energy, wind mills, induction generator, load management.

\section{Introduction}

Fossil fuel is still serving as the major resource forgenerating electricity in several countries. The depletion offossil fuel reserves are a challenge facing the growing energydemands of the day. Furthermore, fossil fuel based electricitygenerators pollute the environment [1]. Therefore, the use ofalternate and renewable energy resources to meet the electricalenergy requirements of the modern world has becomeincreasingly important nowadays. In an attempt to resolve theresidential electrical energy consumption in homes modularenergy extraction equipment working with solar and windenergy is presented. By and large, the installation of windmillplant is an expensive affair and it has cost constraints for itsimplementation. We reduce this constraint by installing a costeffective medium capacity windmill supplying electricity toelectric grid of the township. Furthermore, the coastal regionsexperiencing heavy winds are liable to create rough seaproducing high sea waves. In such circumstances, sea waveenergy extraction plants can be installed in selected spots formeeting further the rest of the electricity requirements of thetownship resulting in self-sustained electricity generation. Stand-alone operation of a squirrel-cage induction generator based WECS with regulated output voltage and frequency requires either an asynchronous link (ac-dc-ac) power electronic converter [2], [3] or a matrix converter.

\section{Home Installed Modular Energy Generators}

\section{System Design Model}

A modular energy extracting unit working on solar energy and wind energy is to be installed in homes. In addition, solar heat extractors are also to be installed in homes for reducing the electricity spent for hot water. We now present the design approach for realizing them.

A. Modular Mini-Electricity Generator Installed at Home: The solar panel with an array of lined PV cells is kept on shadow free zone in the roof and its direction is automatically adjusted towards the direction of the sun as to maximize extracting the energy. The windmill in turn gets aligned to the direction of wind automatically due to its special geometrical features consisting of gliding tail part. A very simple schematic of the unit is shown in Fig.1. The electrical energy extracted from both the solar and wind are saved as DC power in an accumulator containing an array of batteries. The DC voltage of PV matrix is boosted up and used to charge the accumulator. On the other hand the unregulated $\mathrm{AC}$ voltage of the windmill is rectified, boosted up and it is used to charge again the same accumulator in parallel form.

The DC voltage of the accumulator is inverted to have the AC voltage of set standard frequency $(50 \mathrm{~Hz}$, Turkish standards) and the power is fed to home or grid of township. A microcontroller senses the voltage and current of PV panel and performs maximum power tracking algorithm. Also, it keeps the PV panel 
automatically along the direction of the sun for maximizing the absorption of solar energy by PV panel. Furthermore, the microcontroller generates necessary chopping signals needed for DC boosters.

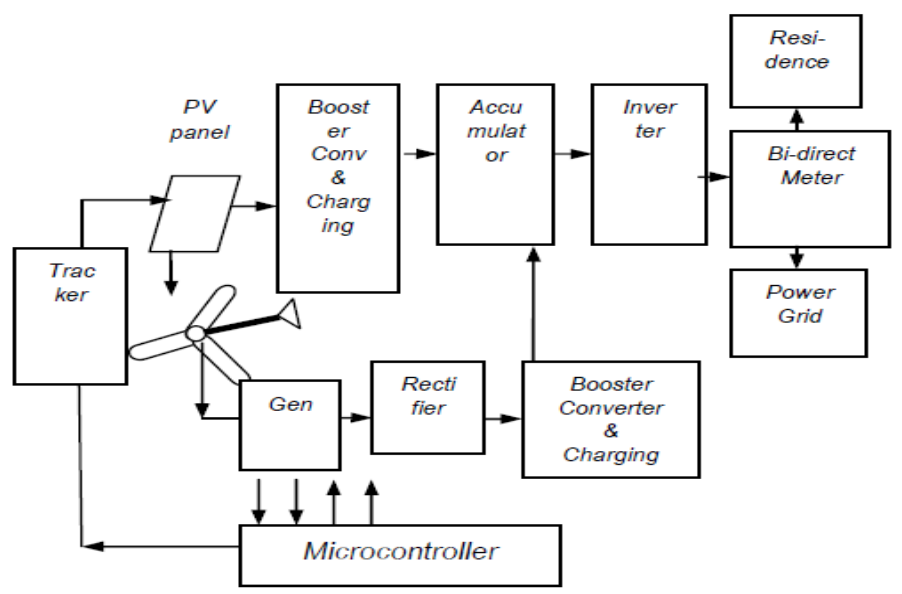

Fig.1. Scheme of Modular Mini-Electricity Generator

The electricity generated from the PV panel and from the windmill is consumed mainly on the spot and therefore the overheads involved in transmission and distribution are avoided.

B. Factors Concerning the Estimation of Optimal Power Capacity of the Modular Power Generator: The mini electricity generator to be installed at homes is to be designed based on requirements on the sites.

i. The type of houses and buildings constructed in the township and the available roof area for fixing PV panels and mini windmill generator.

ii. The average energy per home consumed in the residential sector.

iii. The location factors concerning the availability of solar energy and wind energy.

iv. The consistency and seasonal variations of solar and wind energy.

A report on the statistical parameters obtained from an island like North Cyprus was made recently [4] and this principle helps in designing mini electricity generators for reaching appropriate power output.

C. PV Panel: The DC voltage generated and power supplied by a photovoltaic system depends on the solar radiation and temperature. The solar panels employ an array of PV cells to develop voltage and its conversion into power. The output characteristics of a solar cell are non-linear and are depending on solar radiation, temperature and load condition. Each curve has a MPP (Maximum Power Point), at which the solar array operates most efficiently. The current flowing in PV cell and its power in terms of PV cell voltage are available in the reports [5,6]. Also, an algorithm to track the MPP has been reported [7] for efficient utilization of the PV array in generating the electricity. We incorporate the algorithm tuned to other parameters of the system extended to the PV array as to optimize the power generation from solar PV array.

D. Solar Tracking: The microcontroller also performs the solar tracking algorithm as to keep the panel always towards the direction of the sun. For this purpose the PV panel is fixed with four photo sensors kept at corners and another one kept at the center $[8,9]$. The voltages of sensors are read by microprocessor and those from that of orthogonal directions are compared and the orientation of the panel is adjusted by stepper motors as to minimize the error signals. The panel is resting on a platform whose angular positions are set in orthogonal directions by two stepper motors. This keeps the direction of the panel adjusted towards the sun always resulting in maximum solar energy captured by the PV panel. When there is no sun for a long time the algorithm keeps the panel in east direction to be ready for next day's tracking. Although the tracking event consumes little power it is negligible compared to the excess power generated by panel due to its aligning towards the sun.

E. Charge Controllers and Inverters: Charge controllers protect the batteries (Accumulator) from over charge and excessive discharge. It disconnects the battery from PV panel when they are fully charged. The operating voltage and PV array current determine the capacity of charge controller. Inverters convert the DC voltage of the battery into AC voltage of standard frequency. When sun is shining or wind is blowing electricity comes from them via inverter. If PV array and windmill make more power than that used in home the excess is sold to the grid. The frequency of AC supply produced by inverters is regulated at a standard value of $50 \mathrm{~Hz}$. 
F. Mini Windmill: Wind power is proportional to the cube of wind speed [10]. Windmills of different capacities are available in practice and being used. We use here a cost effective mini wind mill installed in the roof of the flat. Windmill generates $\mathrm{AC}$ voltage and its frequency is unregulated and is varying in accordance with the wind speed. As we need to have standard frequency of electric power given to some sensitive household appliances the AC voltage from windmill is rectified and the DC voltage is boosted up and charged in the accumulator. In order to extract maximum wind energy the plane of blades should face the direction of the wind. Since the windmill is of small in size a mechanical gliding tail attached to the windmill gets it aligned automatically towards the wind direction and no electronic adjustment is needed for its direction.

\section{Solar Energy Generation}

Room heaters may be needed in townships located on colder environmental areas. This project proposes to extract efficiently the solar heat energy and transfer it to the hot water circulating to the room heater radiators. Two parabolic solar reflectors are installed in open space where solar radiation falls on it without any shadows. At the focal point of each reflector is fitted with a metallic chamber connected with a hot water pipeline circulating the hot water to the heat radiators. Fig.2 shows its simple schematic. Also, as the heat produced may be insufficient for the radiator, the hot water is heated with a gas burner whose gas flow is controlled by a microcontroller.

Microcontroller and its Tasks: The microcontroller implemented with PIC family performs the following tasks. i. performs solar tracking involved in sensing the photo sensor voltages, processing them and issuing control drive to stepper motor as to adjust the angular positions of the solar panel. ii. the booster converter and the inverter are driven with timed chopping signal as programmed in a timer interfaced to microprocessor. iii. The voltage and current from the PV array are read and power tracking algorithm is performed. In short all monitoring and control operations are performed by the microcontroller.

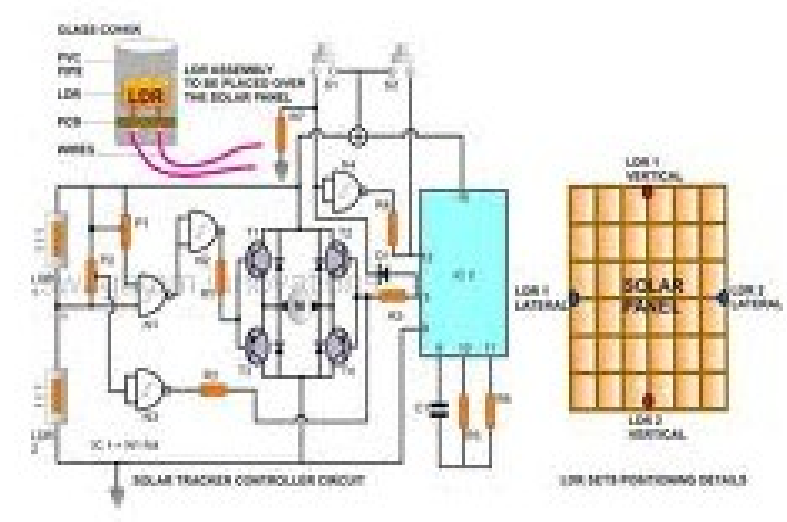

Fig.2.Design circuit for solar energy.

After passing thorough the radiators the water gets back to the parabolic reflector and passes to the water heater. If desired, the pipeline can be extended to the hot water taps also inside the rooms. This arrangement minimizes the gas supplied to the burner of the water heater. In order to reach the desired temperature inside the room the microprocessor reads the set temperature as analog voltage through a potentiometer and also the present room temperature from a temperature sensor. These two voltages are digitized using a MUX ADC and read by the microprocessor. The room temperature is compared with the set temperature and a decision is made to drive the stepper to increase the gas valve opening or decrease it such that the flame is set to reach the desired temperature inside room. In a display unit the microprocessor displays the present room temperature. More than two parabolic reflectors can be used in the setup and the pipeline, if there are no space constraints. Since the solar energy is focused to a point this heats up much more efficiently than the normal flat panel solar heaters and by this way water can be heated up even to the boiling point. The circulating hot water can be connected to reach selected hot water taps. Parabolic heat collector is used to maximize receiving the heat energy. It is also made of shining reflector surface such that reflection efficiency is nearing to unity. The material itself is a heat insulator keeping the heat losses minimum. The plane heat wave front from sun incident on the parabolic dish gets converted into spherical wave and focuses to the focal point of the parabolic dish. The metallic vessel kept focal point is coated with materials absorbing heat wave completely without re-radiation. 

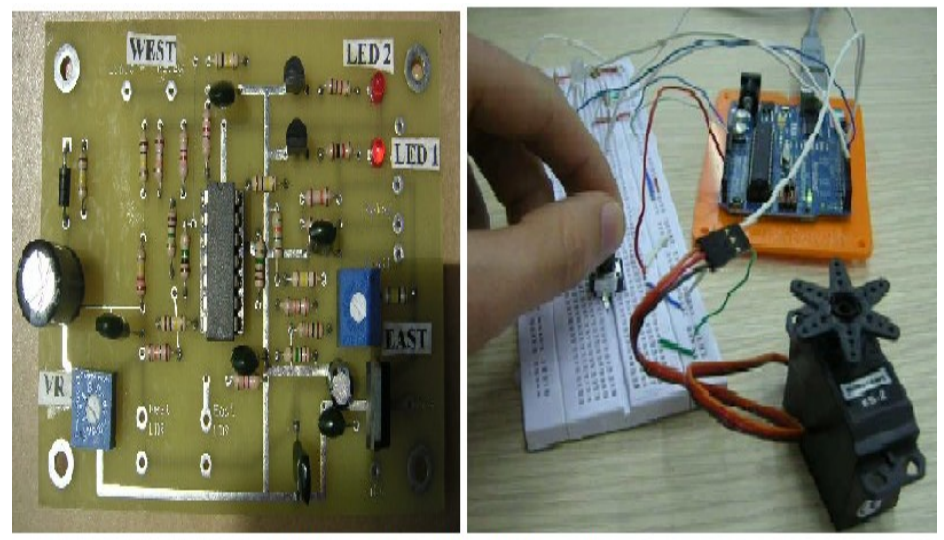

Hardware implemenation of design circuit

Fig.3. Hardware implementation.

\section{Medium Sized Windmill Plant}

Large capacity windmills have their initial investments high and energy producers have to consider several factors before installing such kinds of windmills. We now are proposing only affordable medium capacity wind mill trading off the cost effectiveness and energy needs. Since coastal areas always have seen breeze this installation of windmill would yield best results. A wind mill plant having a group of 8 windmills, as shown in a simple schematic in Fig.4, are controlled by microcontroller to test and adjust the direction of each windmill. A mini test windmill is used to sense the present direction of the wind and the directions of other wind mills are adjusted simultaneously to the same direction of test windmill. As before, the microcontroller also controls the chargers of the accumulator and inverter chopping circuits. The AC voltage generated from all windmills are synchronously added up and given to the rectifier unit.

The rectified DC voltage is boosted up and the accumulator is charged accordingly. The inverter gets the frequency stabilized $\mathrm{AC}$ voltage and the electric power is transmitted as in conventional manner to the electric power grid of the township. Fig. 4 shows the schematic diagram of the system under consideration. The wind turbine is connected to the rotor of the induction generator through a step-up gear box. At the stator side of the generator, there is an excitation capacitor bank in parallel with a dump load, the VSI, and the consumer load.

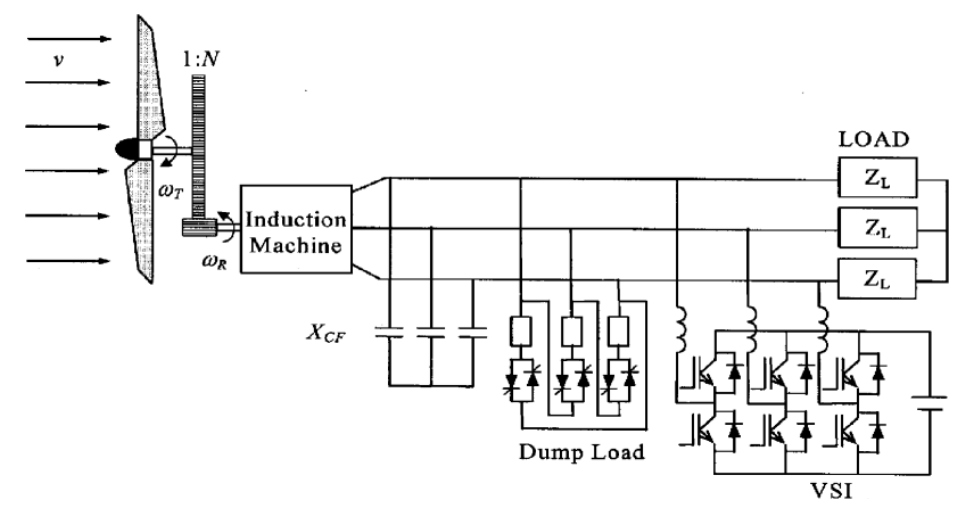

Fig.4. the WECS regulated with a single static power converter.

The ac inductorthat connects the VSI to the induction generator is chosen sothat it provides, along with the excitation capacitor, a low-passfilter for the current harmonics created by the VSI. Tunedfilters for the current harmonics of the dump load can be implementedby splitting the excitation capacitor bank and addinginductors in series. The size of the battery bank should be calculatedaccording to the local wind speed and load profiles and desired reliability. 


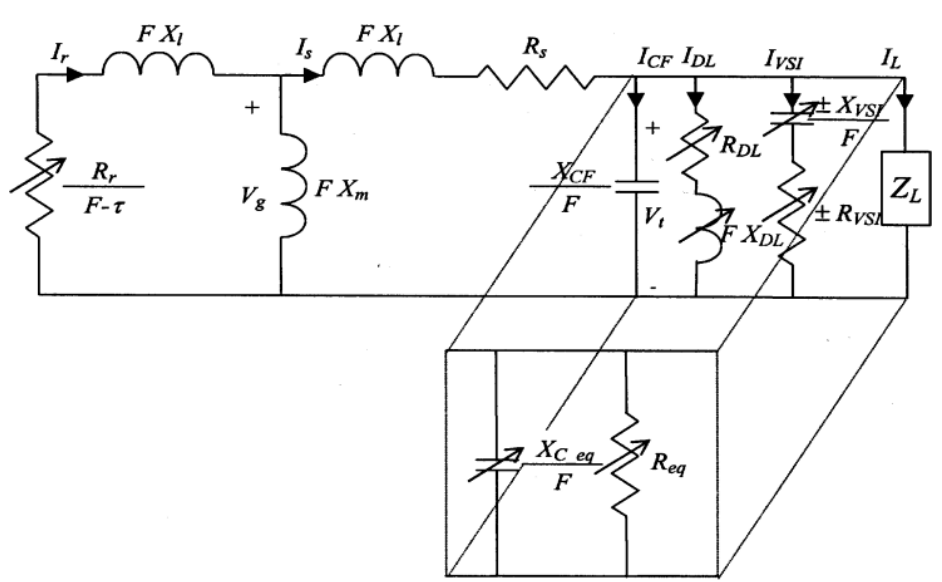

Fig. 5. Single-phase equivalent circuit of the induction generator with theshunt capacitor, dump load, VSI, and load.

Fig. 5 shows the per-unit per-phase steady-state equivalentcircuit of the system (squirrel-cage induction generator, excitationcapacitor bank, dump load, VSI, and consumer load)normalized to the base frequency. The dump load is modeledby a variable resistor (RDL) and a variable inductive reactance(XDL) to represent the fact that the active and reactive power absorbed by the dump load varies with the firing angle $(\alpha)$ of thethyristors. The VSI, including the ac side inductance and batterybank, is modeled by a variable capacitive reactance (XVSI)in series with a variable resistor (RVSI).

\section{Experimentaland Simulation Results}

Solar Energy: The microcontroller used here performs the following. Itreads the sensor signals of $i$. environment temperature ii.steam inflow to turbine and iii. boiler water inflow andiv. water level in overhead tank. The water level is maintainedabove the reference level by microcontroller with the sensed level and switching ON or OFF the water pump filling thetank. It arranges to display also the sensed parameters like temperature, steam inflow and feed water inflow in sequential manner. The boiler has all instrumentation system such as pressure maintenance and water level control. After transferring the energy to turbine the steam gets condensed and returned to the feed water.

Wind Energy: The effectiveness of the VSI for regulating the magnitude and frequency of the generated voltage was verified by means of digital simulations with MATLAB. A squirrel-cage induction generator recently developed by SIMULINK and kindly made available to the authors of this paper allows the user to set all parameters of the machine including the magnetization curve. A model for a wind turbine based on the $\mathrm{CP}$ versus $\lambda$ curve and that also includes the moment of inertia was developed in house.

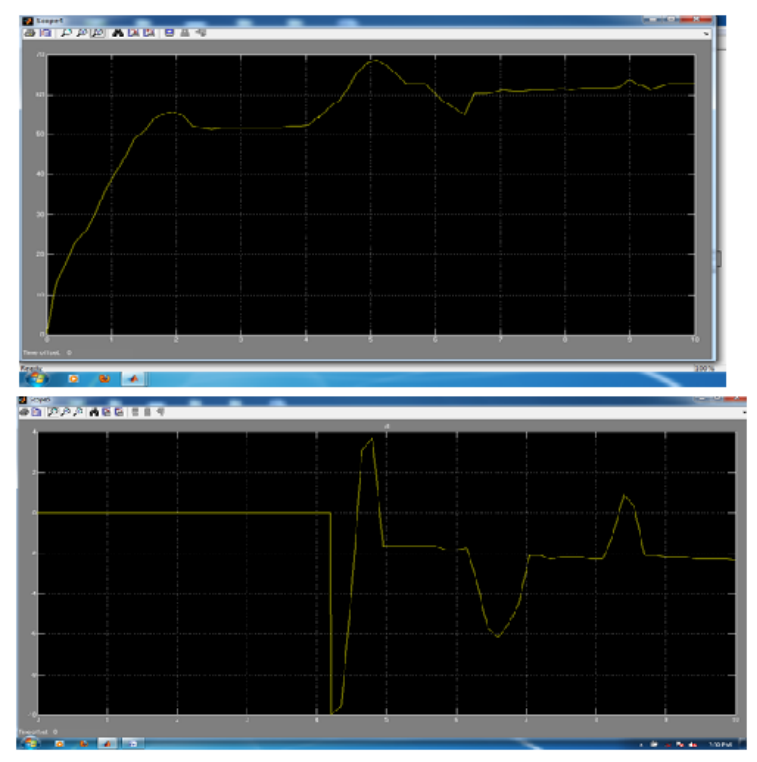

Fig.6. Behavior of the system due to a wind speed variations. 


\section{Conclusion}

Unlike fossil fuel based electricity generators the modular electricity generators do not cause pollution to the environment. With the installation of modular electricity generators the residences are generating electricity while consuming and the instantaneous excess energy generated is sold to the grid. Because of open space environment the residential areas located in coastal regions receive relatively a large quantum of solar energy and wind energy. Sea breeze sets on quite frequently and becomes occasionally heavy. This paper has presented a self-sustained modular approach to resolve the energy needs of the township with freely available solar and wind energy.

\section{References}

[1] http://leahy.senate.gov/issues/environment/ca_stats.html, 2009.

[2] R. M. Hillowala and A. M. Sharaf, "A utility interactive wind energy conversion scheme with an asynchronous DC link using a supplementary control loop,” IEEE Trans. Energy Convers., vol. 9, no. 3, pp. 558-563, Sep. 1994.

[3] M. G. Sim oes, B. K. Bose, and R. J. Spiegel, "Fuzzy logic based intelligent control of a variable speed cage machine wind generation system,” IEEE Trans. Power Electron., vol. 12, no. 1, pp. 87-95, Jan. 1997.

[4] K. Balasubramanian and A. Cellatoglu, "Optimal Utilization of Renewable Energy Resources in North Cyprus : A proposed Model", Proceedings of the 2nd International Conference on Computer and Electrical Engineering, Dubai, Dec 2009, pp 178-183.

[5] Carstensen, J., Popkirov, G., Bahr, J. and Föll, H., “ An Advanced LBIC Measurement Technique for Solar Cell Local Characterization', Solar Energy Materials and Solar Cell , 76, 4, 2003, pp 599-611.

[6] Li,D.H.W., Cheung, G.H.W. and Lam,J.C., "Analysis of The Operational Performance and Efficiency Characteristic for Photovoltaic System in Hong Kong”, Energy Conversion and Management, 46, 2005, pp 1107-1118.

[7] Joe-Air Jiang, Tsong-Liang Huang, Ying-Tung Hsiao and Chia-Hong Chen, "Maximum Power Tracking for photovoltaic Power Systems", Tamkang Journal of Science and Engineering, Vol 8, No 2, pp 147-153, 2005.

[8] B.Koyuncu and K.Balasubramanian, "Microprocessor Controlled Automatic Sun Tracker", IEEE Trans on Cons. Electron, Vol 37, No 4, Nov 1991, pp 913-917.

[9] K.Balasubramanian and A.Cellatoglu, "Improvements in Home Automation Strategies for Designing Apparatus for Efficient Smart Home", IEEE Trans. on Cons. Electronics, Vol 54, No 4, Nov 2008, pp 1681-1687.

[10] A.Yasli, Investigations on the Design of Dual Renewable Energy Systems for Use in North Cyprus, MS Thesis Dissertation, European University of Lefke, North Cyprus, 2009. 